\title{
Interfacial studies on different pile materials and their roughness characterisation using 3D optical profilometer
}

\author{
G. Sreelakshmi ${ }^{1}$ (D) M. N. Asha ${ }^{2}$ (D) L. Thejus ${ }^{2}$ (D)
}

Received: 13 April 2021 / Accepted: 29 June 2021 / Published online: 17 August 2021

(c) The Author(s), under exclusive licence to Springer Nature Switzerland AG 2021

\begin{abstract}
Piles are slender members made of concrete, steel, aluminium or timber installed in the ground to transfer the loads to soils at some significant depth below the base of the structure. The material property of the pile influences load-deformation response, bearing capacity, surface roughness and interfacial shear behaviour. The current study aims at assessing interfacial friction through a series of laboratory studies using three different pile materials, viz. concrete, wood and aluminium with sand as infill material. The surface roughness of three pile materials is analysed using a three-dimensional optical profilometer. Among the three pile materials considered for the study, the abrasive action of infill on concrete is more evident due to granular particles' intrusion on the cracked concrete surface. Wood and aluminium specimens developed enhanced tangential and adhesive action after shearing action. The three-dimensional profilometer studies could capture the abrasive action and subsequent wear and tear of the pile material.
\end{abstract}

Keywords Friction angle $\cdot$ Interface $\cdot$ Pile material $\cdot$ Surface roughness $\cdot$ Skin friction

\section{List of symbols}

$\mathrm{D}_{10} \quad$ Diameter refers to $10 \%$ finer in the particle-size

$\mathrm{D}_{30} \quad$ Diameter refers to $30 \%$ finer in the particle-size

$\mathrm{D}_{60} \quad$ Diameter refers to $60 \%$ finer in the particle-size

$\mathrm{D}_{50} \quad$ Diameter refers to $50 \%$ finer in the particle-

size or Mean particle diameter

$\mathrm{C}_{\mathrm{u}} \quad$ Coefficient of uniformity

$\mathrm{C}_{\mathrm{c}} \quad$ Coefficient of curvature

$\gamma_{d}(\max )$ Maximum dry unit weight

$\gamma_{d}(\min ) \quad$ Minimum dry unit weight

$\gamma_{d}$ (test) Dry density of the infill

$\Phi \quad$ Peak Angle of internal/interface friction

$\varphi^{\prime} \quad$ Post peak Angle of internal/interface friction

G. Sreelakshmi

sreelakshmi.g@cmrit.ac.in

M. N. Asha

asha.n@cmrit.ac.in

L. Thejus

thejus19999@gmail.com

1 Department of Civil Engineering (VTU RRC), CMR Institute of Technology, 132, AECS Layout, IT Park Road, Bengaluru 560 037, India

2 Department of Civil Engineering, CMR Institute of Technology, 132, AECS Layout, IT Park Road, Bengaluru 560 037, India
$R_{a} \quad$ Absolute roughness

$R_{t} \quad$ Total height

$R_{n} \quad$ Normalised roughness

$R_{m r} \quad$ Relative material ratio

$S_{q} \quad$ Root mean square height

$S_{s k} \quad$ Skewness

$S_{k u} \quad$ Kurtosis

$S_{p} \quad$ Peak height

$S_{v} \quad$ Pit depth

$S_{z} \quad$ Maximum depth

\section{Introduction}

Traditional and modern pile foundations employ wood, steel, aluminium, concrete, or composite materials for prefabricated sections, cast in situ or driven piles. Steel or aluminium piles are available in wide ranges of size and length and can penetrate all types of load-bearing soil strata. But they require adequate protection against deterioration when desired in the marine environment. Sheet piles, fender piles, and dolphins are the most common types of wooden piles, and they retain walls, basements, docks, and harbours and protect river banks from landslides. Wooden piles are easier to handle with tapered sections but cannot withstand handling and driving stresses. Whereas cast in situ or precast 
concrete pile transfers heavy load from superstructure to subsoil through surface and tip resistances. In friction type of cast in situ or driven piles, load transfer is through shear force generated due to surface friction between soil-pile interface, and the friction factor influences the pile's shear behaviour, which directly depends on the material's surface undulations. Compared to steel or wooden piles, concrete piles are durable and can withstand driving stresses but are very bulky to handle and install in all type of environments.

Generally, pile foundations are subjected to various loading conditions, temperature fluctuations, and infill conditions throughout their lifetime, resulting in a gradual loss of piles' cross-sectional area and causes a reduction in load-bearing capacity. So, it is crucial to retrofit the weakened foundations by reconstructing and restoring the deteriorated materials to regain actual pile capacity $[1,2]$. Furthermore, for piles adopted in ports, harbour, and offshore structures, it might be necessary to reinforce the damaged ones to piles of higher bearing capacity. So, to enhance the performance and integrity of structures founded on pile foundations, it is necessary to assess and investigate the durability of the pile material through interfacial and surface texture analysis.

The study of interfacial behaviour of materials started in 1936 by Parsons using shear boxes of different sizes for conducting the direct shear test and concluded that shear parameters like friction angle decreased considerably with box dimensions [3]. Several studies conducted on modified strain-controlled direct shear set-up focused on investigating the shearing mechanism of soil through stress function based on the horizontal shearing force and interface angle of friction and compared them with simple direct shear, ring shear results [4-7]. These parametric studies also explored the effect of interface orientation, displacement scale, normal stress, and particle size distribution of interfacial materials. Potyondy (1961) determined surface friction in cohesive and cohesionless construction materials using controlled shear box tests and highlighted its importance on soils' bearing capacity [8].

Researchers also studied the influence of interfacial friction, surface features, adhesive behaviour of particles, gradation, particle sizes and shapes during the shearing process [9-11]. They concluded that the stresses and strains generated and transmitted at the interface determine the material's interfacial strength and resistance. Few investigations carried on multi sleeve penetrometer attachment, and CPT estimated the variation of shear strength and roughness in sandy and silty soil $[10,11]$. Ho et al.(2011) conducted large-scale ring shear interface tests using silica sand-steel and reported that grain crushing influenced the displacement dependent critical angle of friction [12]. Vangala and Latha Gali (2016) studied the effect of sand particle size and surface deformations of reinforcing material [13]. They concluded that peak interfacial friction and dilation angles influenced interlocking behaviour under direct shear conditions. Jeong and Park (2019) investigated the effect of the shear strength of gravel using ring shear tests by inducing smooth and rough surfaces inside a shear box [14]. Wang et al. (2020) carried large scale interfacial direct shear tests using concrete plates in silty clay and estimated the variation of roughness-dependent shear parameters by adopting piezo sensors [15]. They concluded that rough-surfaced test boxes detected significant grain crushing and change in strain behaviour than smooth surfaces. The results also specified the significance of surface roughness for shear strength determination of granular materials.

The surface characteristics of the material is an important parameter that adversely affects material deformations, degree of wear and tear of surfaces, surface and subsurface stresses and strains. But it depends on the material's surface friction, material composition, shear behaviour, and loading conditions. Though most of the literature studies concentrated on laboratory shear tests to determine interfacial friction of the material, only a few researchers like [16-18] focused on forensic studies to investigate surface roughness and its asperities. The experiments performed to estimate the effect of particle sizes on shear strength could establish a correlation between normalised surface roughness and critical-state interface friction angle. Studies also concluded that grain size distribution significantly affected friction angle and reported a rapid movement of soil particles around shear concentration zones in sandy and gravelly soils.

The effect of surface roughness on skin friction and driven piles' capacity has always been a topic of interest. Generally, loads are transferred mainly through skin friction developed along the pile surface's outer shaft and surrounding infill medium for friction piles. But depending on the pile material, the load transfer rate is affected by the shear stress rate mobilised at the pile-soil interface. Alawneh et al. (1999) defined the roughness parameters based on the skin friction of driven piles and dilation characteristics of the infills [19]. They stated that substantial changes occur in the microstructural behaviour of embedded medium during the pile driving process.

Canakci et al. (2016) used experimental and two-dimensional roughness studies to examine interfacial properties between organic soil and materials such as concrete, steel, and wood for varying moisture and granular soil content [20]. According to their test results, pile material and organic soil's frictional resistance influenced soil's moisture content, granular content, the state of the material, and surface roughness.

Muszyński and Wyjadłowski (2019) adopted a threedimensional laser scanner technique to determine the surface properties of concrete pile material, and studies concluded that morphological assessments could predict the pile's skin friction capacities [21]. Wang et al. (2020) carried interfacial 
studies using concrete plates of varying surface grouting and cohesive soil as infill material and examined the influence of skin friction on the bearing capacity of bored piles[22]. They concluded that concrete grouting resulted in a change of compressive to dilative soil stress state and increased shear band thickness near interface regions.

Few researchers performed centrifugal studies to estimate the roughness properties of jacked and laterally loaded piles [23-25]. However, they concluded that material property, loading, and infill density influenced the pile surface morphology and shaft friction generated during pile progression. Kou et al. (2021) carried direct shear tests to estimate the interfacial properties of steel pile plates and calcareous sand and established that the surface morphology of steel plates significantly influenced the interfacial friction angle at contact zones [26].

Majority of studies in the literature concentrated on the type of infill, particle size, moisture content, stress conditions, shear mechanism, effect of surface treatment and twodimensional surface roughness. However, fewer studies have discussed the type of pile material, suitability of material, infill-material interaction, and shear transmission under specific infill conditions. Shear-induced interfacial friction is an important parameter that needs investigation in the soilstructure interaction analysis. The present work explores the interface shear behaviour using direct shear test for three different pile materials viz; Concrete, Aluminium and Wood with respect to sandy soil as an infill medium. In addition, a three-dimensional optical profilometer is used to investigate variation in the surface roughness of unsheared and sheared pile materials. The research aims to evaluate the intrusive behaviour of the infill medium against a sheared surface and develop a clear understanding of the load transmission mechanism between sheared pile surface and the founded soil in a realistic environment. The study also examines the suitability and durability of the pile material through interfacial and surface texture analysis.

\section{Methodology}

The summary of the methods used in the experimental and profilometric studies are listed below:

a. Initial characterisation of soil

b. Selection and proportioning of plate specimens

c. Determination of interfacial frictional parameters using direct shear tests

d. Comparison of shear and roughness parameters for the scaled surface portion

e. Roughness characterisation of plate specimen at pre and post shear stages using optical profilometers f. Interfacial and surface texture analysis of different pile materials under specific infill conditions

g. Discuss the adequacy of international codes in estimating pile friction and comparison with experimental results.

\section{Experimental set-up and materials}

\section{Initial characterisation and proportioning of plate specimens}

The infill material used for the present study is sand, and its physical characteristics were determined using the methods outlined in ASTM C128-01 and D6528-17 codes [27, 28]. Table 1 lists the infill's properties, and Fig. 1 depicts the grain size distribution curve for the infill used in this analysis. The relative density of infill material, i.e., sand, is maintained at $65 \%$ (dry unit weight, $\gamma_{\mathrm{d}}($ test $)=16.5 \mathrm{kN} / \mathrm{m}^{3}$ ) for the direct shear tests.

Interfacial direct shear tests under varying vertical stress stages used three different test plates of $6 \mathrm{~cm} \times 6 \mathrm{~cm} \times 2.0 \mathrm{~cm}$, with pinewood selected as the wooden test plate, free from surface undulations and surface texture plywood like finish. The concrete test plate with fine aggregates of size $4.75 \mathrm{~mm}$ and cement of grade 56 cast using a wooden box of $6 \mathrm{~cm} \times 6 \mathrm{~cm} \times 2.5 \mathrm{~cm}$. Figure 2 represents a photograph of the test specimens adopted in the present study.

\section{Direct shear test set-up}

The interfacial direct shear experiments are performed with the pile material at the interface as the infill, as surface roughness significantly influences interfacial friction at the

Table 1 Properties of the infill used in the study

\begin{tabular}{ll}
\hline Infill property & \\
\hline Grain size analysis & \\
$\mathrm{D}_{10}$ & $0.17 \mathrm{~mm}$ \\
$\mathrm{D}_{30}$ & $0.7 \mathrm{~mm}$ \\
$\mathrm{D}_{50}$ & $1.2 \mathrm{~mm}$ \\
Soil classification & Well graded sand \\
Coefficient of uniformity, $\mathrm{C}_{\mathrm{u}}$ & 7.05 \\
Coefficient of curvature, Cc & 2.4 \\
Specific gravity & 2.66 \\
Maximum dry unit weight, $\gamma_{\mathrm{d}}(\max )$ & $20.1 \mathrm{kN} / \mathrm{m}^{3}$ \\
Minimum dry unit weight, $\gamma_{\mathrm{d}}(\min )$ & $12.3 \mathrm{kN} / \mathrm{m}^{3}$ \\
Dry unit weight of the infill, $\gamma_{\mathrm{d}}($ test $)$ & $16.5 \mathrm{kN} / \mathrm{m}^{3}$ \\
Maximum void ratio & 0.991 \\
Minimum void ratio & 0.298
\end{tabular}


Fig. 1 Grain size distribution curve for the infill material

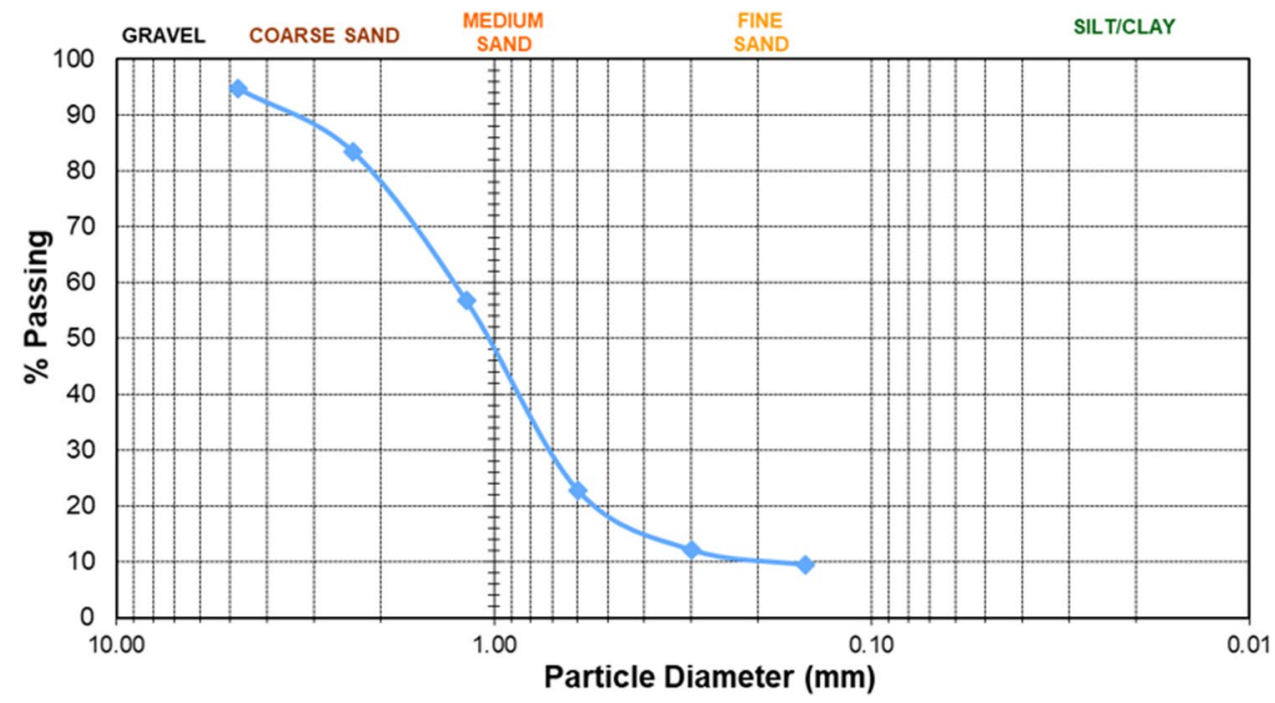

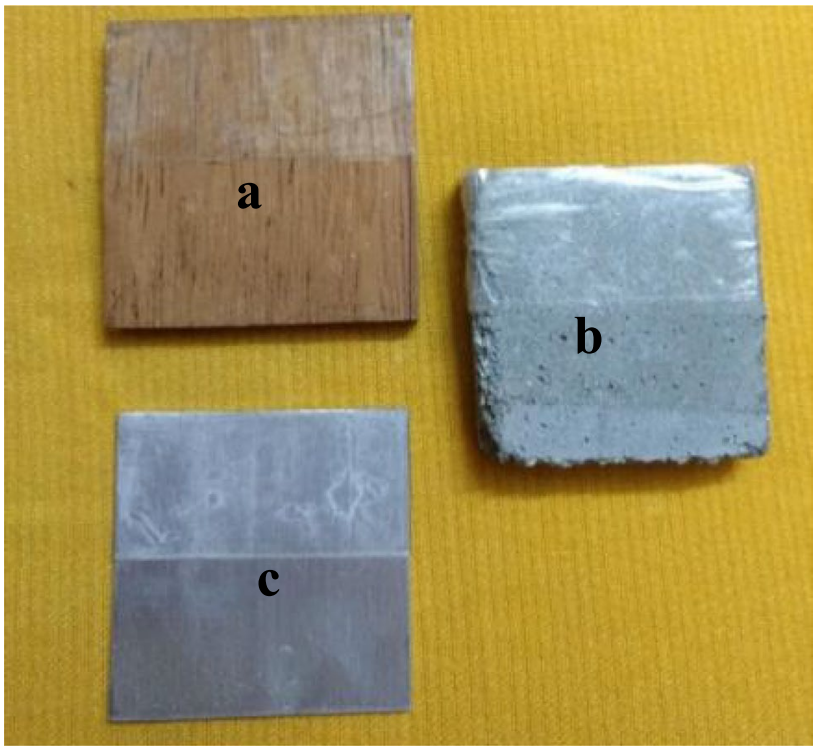

Fig. 2 Photographs of the test specimens a wood, $\mathbf{b}$ concrete, $\mathbf{c}$ aluminium pile-soil interface. First, the infill medium is tamped in the shear box at a rate of 20 blows per layer to obtain a dry unit weight of $16.5 \mathrm{kN} / \mathrm{m}^{3}$. Next, the test plate is positioned in the centre of the box when the sand level reaches half the shear box's height, and the remaining sand is poured to a predetermined density to estimate sand pile interfacial friction. When sheared at a constant rate, the corresponding dial gauge (horizontal displacements) and proving ring readings (Shear load) are taken continuously until the horizontal shear load peaks and falls or $20 \%$ longitudinal displacement, whichever occurs first. The experiment is repeated for each test plate at four normal stresses viz., $0.05 \mathrm{~N} / \mathrm{mm}^{2}, 0.10 \mathrm{~N} /$ $\mathrm{mm}^{2}, 0.15 \mathrm{~N} / \mathrm{mm}^{2}$ and $0.20 \mathrm{~N} / \mathrm{mm}^{2}$ respectively.

Figure 3 shows the schematic line sketch of the test set-up, and Fig. 4 shows the direct shear set up with the aluminium plate placed at the middle. These observations are multiplied with the respective least counts/proving ring constants to obtain shear stress vs horizontal displacement graphs.
Fig. 3 Line sketch of the test set-up

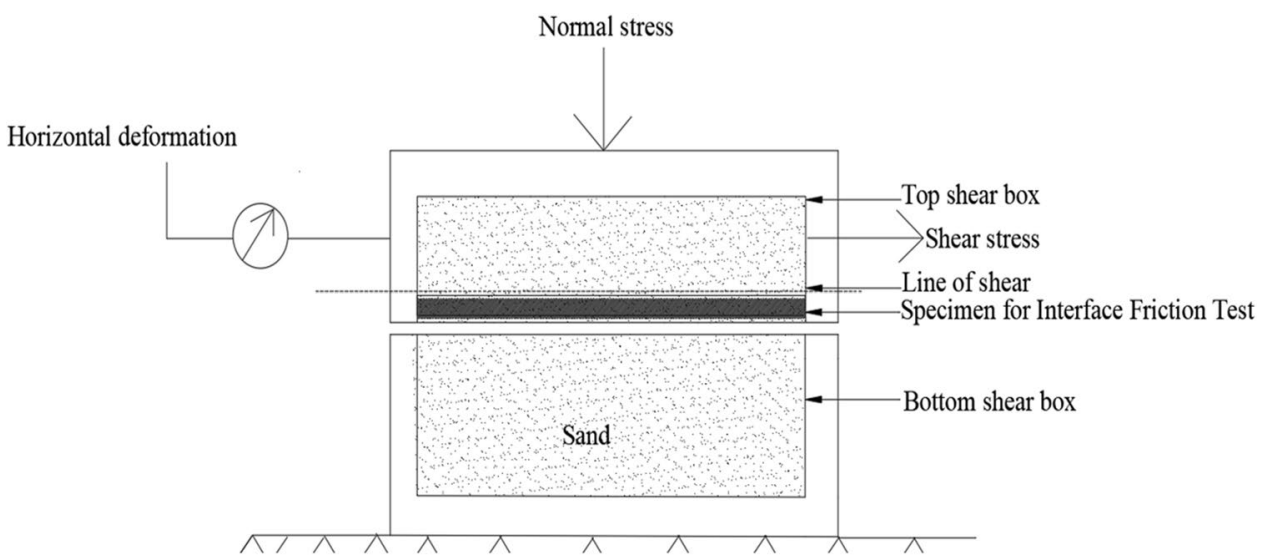


Fig. 4 Direct shear box without and with the test plate

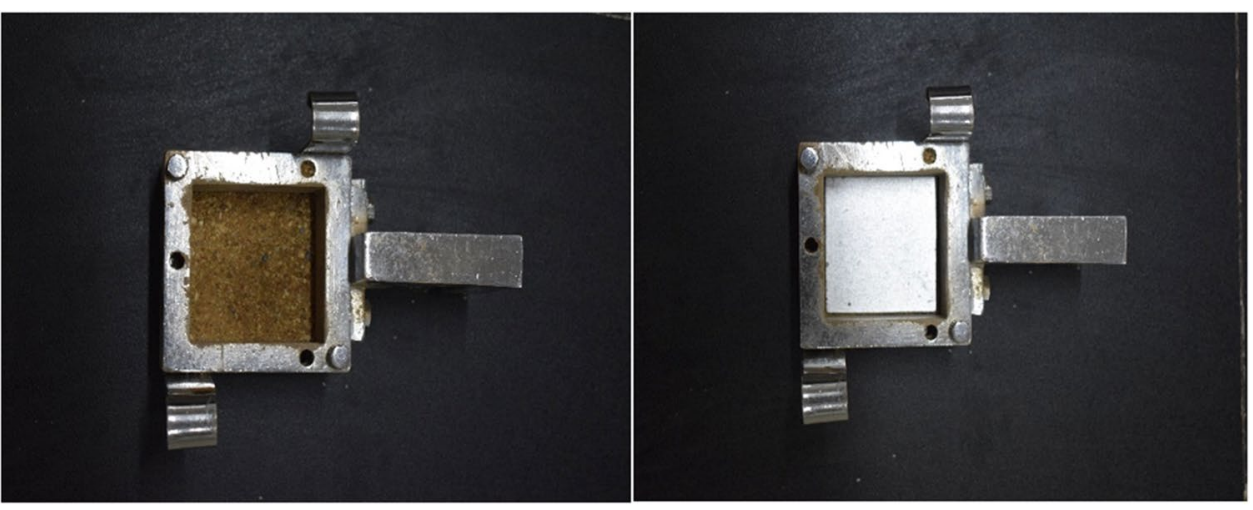

\section{Roughness test setup}

A three-dimensional optical surface profiler performed the surface roughness studies of three specimens viz; Wood, Concrete and Aluminium before(pre) and after(post) shear tests. The three-dimensional profiler (New View ${ }^{\text {TM }}$ 9000, Zygo cooperation, Ametek ultra-precision technologies) has a high sensitivity of $1.9 \mathrm{MP}$ sensor with $150 \mathrm{~mm}$ travel and 4 degrees of tilt along with $\mathrm{X} / \mathrm{Y}$ directions. Optical profilers have interference microscopes that measure optical path differences or height variations between test and reference surface and give surface roughness using the wavelength of light. The light source divides into two parts; the first part reflects through test material by passing through the objective lens, and another half of the light beam reflects on the reference mirror. The beams from the splitter beam and the test surface recombines, through which constructive and destructive interference, known as interference fringes, is created in the form of light and dark bands passed into a digital camera. This optical colour band difference represents the half-wavelength difference between the reference and test surface. The three-dimensional noncontact optical metrology tool named TalySurf CCI with a lateral resolution of 0.4 to $0.6 \mu \mathrm{m}$ calculates the wavelength height difference across a surface, 3D surface formation, waviness and surface roughness [29]. Figure 5 shows the actual photograph of the 3D Optical Profilometer used for the study.

\section{Roughness parameters used for two and three-dimensional surface roughness study as per ISO 4287:1997 and ISO 25178-2: 2012}

This section defines various parameters used for describing two and three-dimensional surface roughness as per ISO 4287:1997 and ISO 25178-2:2012 [30, 31]. The surface roughness of materials for a two-dimensional roughness study are quantified through the amplitude parameters like $R_{a}, R_{t}, R_{n}$ expressed in units of micrometres and $R_{m r}$ as
Fig. 5 Photograph of the 3D optical profilometer

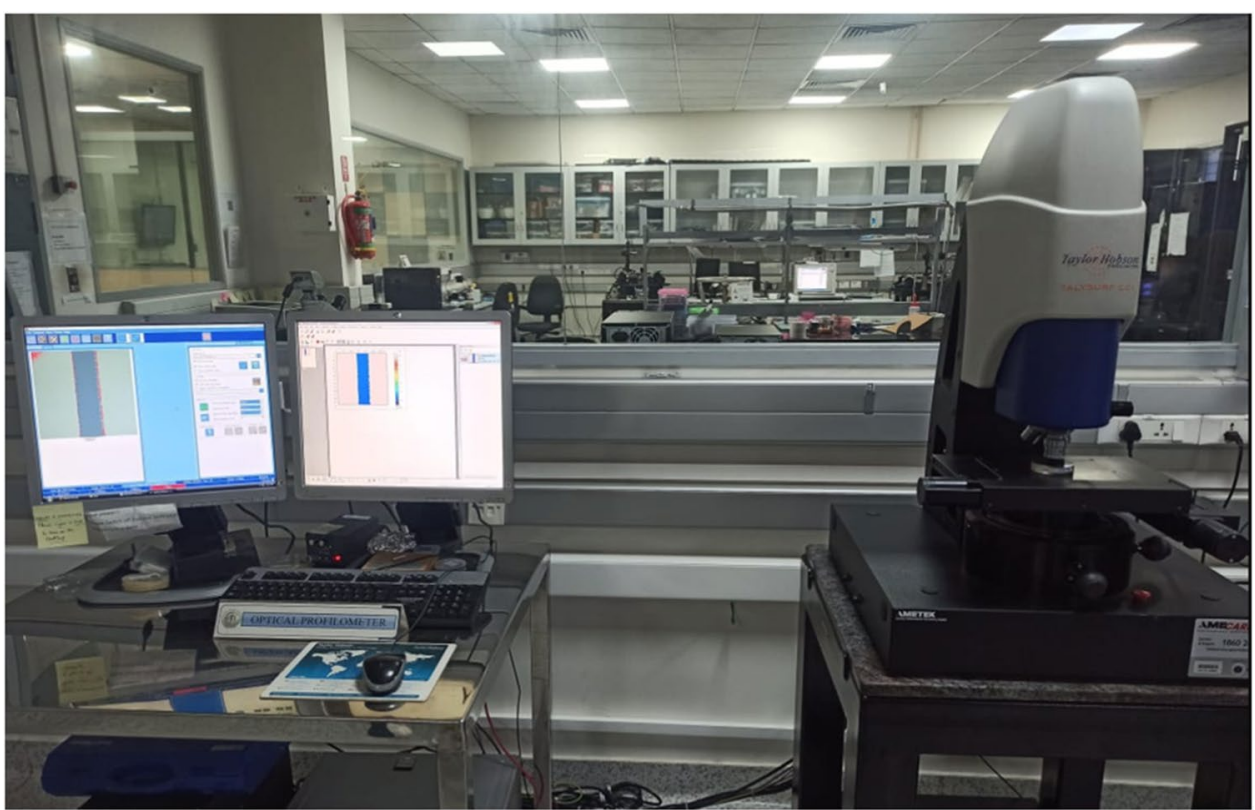


percentage. These parameters define roughness characteristics and material ratio that influences the interfacial shear behaviour between sand particles and plate specimens [ 5 , $6,10,17]$. The parameters are defined as follows [30, 31]:

- Absolute roughness $R_{a}$ : It is the average of centreline roughness values as presented in Eq. 1

$$
R_{a}=\frac{1}{L_{m}} \int_{0}^{L_{m}} Z_{i}
$$

$z_{i}$ is the absolute ordinate, $L_{m}$ is the travel length.

- Total height $R_{t}$ : It is the highest distance measured from peak to valley over the entire profile.

- Normalised roughness $R_{n}$ : It is the ratio of maximum roughness $R_{t}$ to mean diameter $D_{50}$ as given in Eq. 2

$$
R_{n}=\frac{R_{t}}{D_{50}}
$$

- Relative material ratio $R_{m r}$ : It is measured in terms of the difference between the referential section's height and profile section height levels.

For understanding interfacial frictional characteristics between pile and soil, it is crucial to quantify the roughness behaviour of pile materials in fine-grained soils through Absolute roughness $R_{a}$, Total height $R_{t}$ and Normalised roughness $R_{n}[5,6,17,23,32,33]$. Figure 6 shows the graphical representation of the two-dimensional roughness parameter for a Travel length $\mathrm{L}$ and step size $\Delta \mathrm{x}$.

The characteristic notation ' $\mathrm{R}$ ' replaced as ' $\mathrm{S}$ ' and ' $\mathrm{z}$ ' (' $\mathrm{z}$ ' is the actual profile height of the element measured in the $\mathrm{X}, \mathrm{Y}$ plane) for describing the three-dimensional surface roughness. Accordingly, the parameters of the Areal method listed as [21, 31, 34]:

- Root mean square height $S_{q}$ : It represents line roughness in a three-dimensional space, not influenced by indentation, surface contamination, and waviness noise (Eq. (3)). where $\mathrm{A}$ is the surface area of the specimen.

$S_{q}=\sqrt{\frac{1}{A} \iint_{0}^{A} Z^{2}(x, y) d x d y}$

- Skewness $S_{s k}$ : It measures deviation in the surface height in the region and evaluates the surface abrasion effect (Eq. (4)).

$S_{s k}=\frac{1}{S_{q}^{3}}\left(\frac{1}{A} \iint_{0}^{A} Z^{3}(x, y) d x d y\right)$

- Kurtosis $S_{k u}$ : It is a measure of flatness or peakiness of the surface in the region and analyses the degree of surface contact (Eq. (5)).

$S_{k u}=\frac{1}{S_{q}^{4}}\left(\frac{1}{A} \iint_{0}^{A} Z^{4}(x, y) d x d y\right)$

- Peak height (maximum) $S_{p}$ : It is the maximum height of peak measured in three-dimensional space (Eq. (6)).

$S_{p}=\max (z(x, y))$

- Pit depth (maximum) $S_{v}$ : It is the maximum height of the valley measured in three-dimensional space (Eq. (7)).

$S_{v}=\min (z(x, y))$

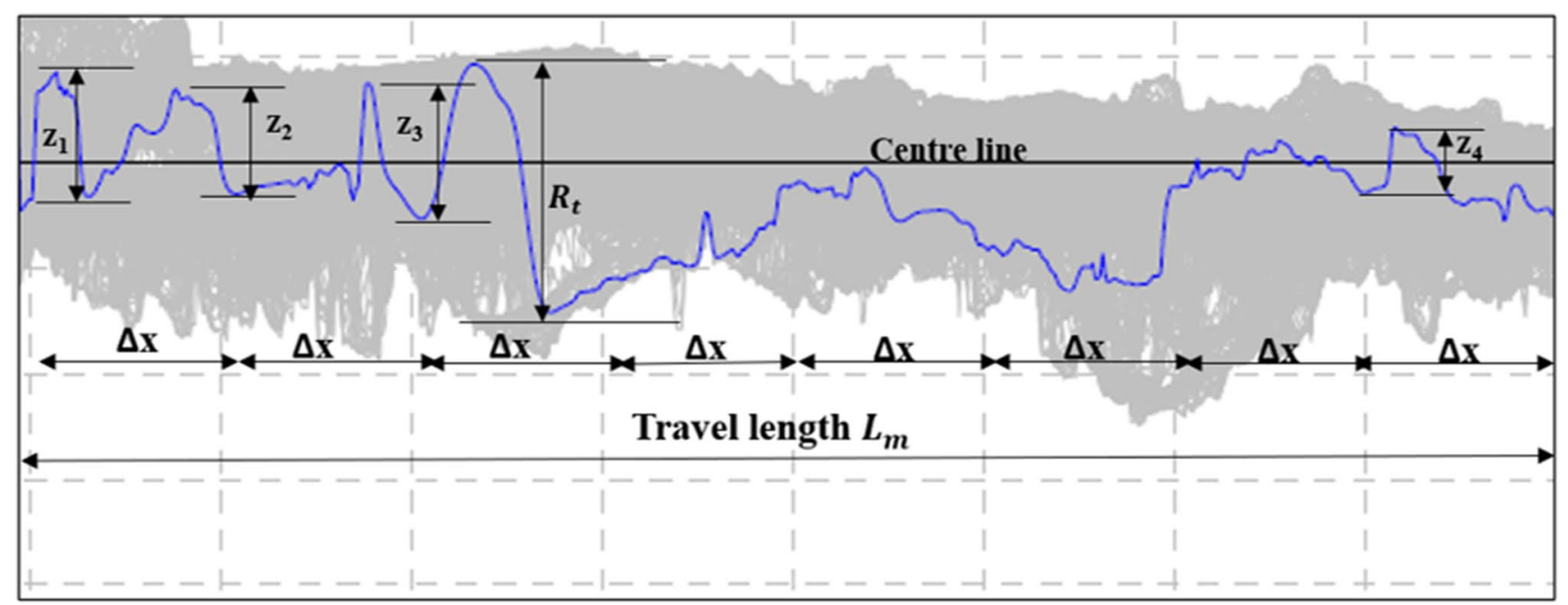

Fig. 6 Graphical representation of roughness parameter for a travel length $\mathrm{L}_{\mathrm{m}}$ and step size $\Delta \mathrm{x}$ 
- Maximum height $S_{z}$ : It is the summation of the average maximum peak height $S_{p}$ and valley depth $S_{v}$ measured in a three-dimensional space (Eq. (8)).

$$
S_{z}=S_{p}+S_{v}
$$

Figure 7a-c shows the graphical representation of threedimensional roughness parameters for the scaled surface portion.

\section{Results and discussion}

\section{Interfacial shear displacement response}

This section presents and discusses the interface shear test results for sand and three different sand-pile materials. Figure $8 \mathrm{a}-\mathrm{d}$ presents the stress-displacement response of sand, concrete, wood and aluminium in interface tests for four different normal stresses viz., $0.05 \mathrm{~N} / \mathrm{mm}^{2}, 0.10 \mathrm{~N} / \mathrm{mm}^{2}$, $0.15 \mathrm{~N} / \mathrm{mm}^{2}$ and $0.20 \mathrm{~N} / \mathrm{mm}^{2}$ respectively.

The shear test results yield the interface shear parameters like cohesion or adhesion, c; friction angle $\varphi$ and $\varphi$ ' (peak and post-peak/critical condition). For example, Fig. 9 shows the shear strength envelope for four different normal stress values $\left(0.05 \mathrm{~N} / \mathrm{mm}^{2}, 0.10 \mathrm{~N} / \mathrm{mm}^{2}, 0.15 \mathrm{~N} / \mathrm{mm}^{2}\right.$ and $0.20 \mathrm{~N} /$ $\mathrm{mm}^{2}$ ) with sand and test plates viz; Concrete, Wood, Aluminium specimens at the interface for both peak and critical state conditions.

A best-fit line is drawn from the normal and shear stress graphs and has an $\mathrm{R}^{2}$ value of $0.98-0.99$. Thus, the test result showed predictable trends in the behaviour of materials wherein interfacial strength increased with normal stress, and Mohr-Coulomb's failure criterion could describe the strength data irrespective of the material's type [20]. Table 2 presents the friction angle, cohesion or adhesion values for different specimens obtained from regression analysis of failure envelopes at peak and critical conditions for Fig. 9.

From Table 2, it is evident that the peak and post-peak coefficient of interfacial friction for concrete is 0.69 and 0.67 , respectively, whereas, for aluminium, it is 0.47 and 0.44 . Thus, the friction angle obtained from the interface test is minimum for aluminium, and friction angle values of concrete and wood obtained are in the same range as reported in the literature [20]. Table 2 also presents the peak and post-peak cohesion values of pile materials at the interface regions. The post shear exhibited a marginal

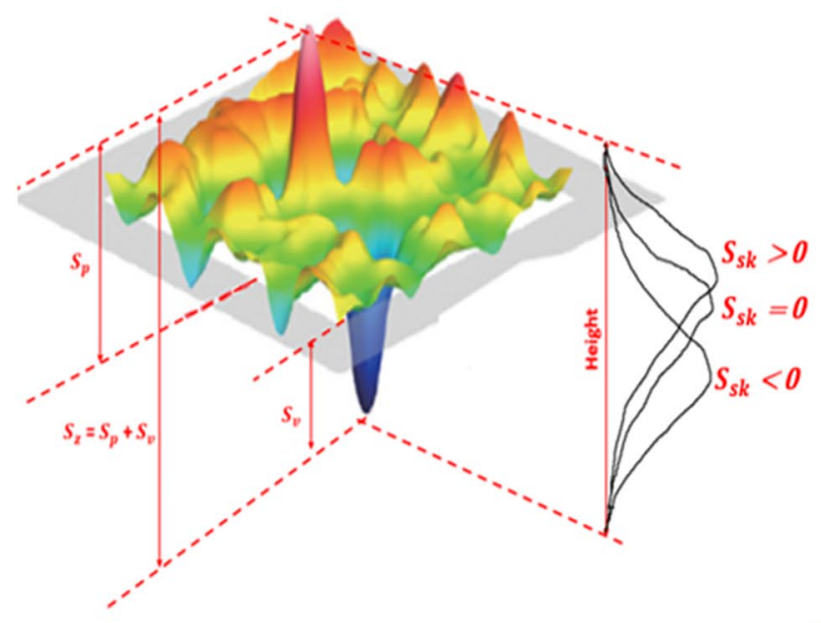

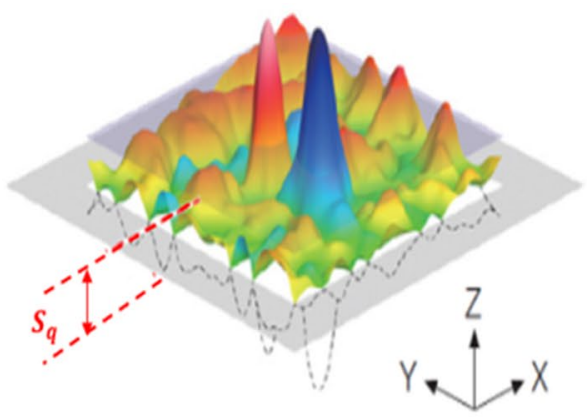

(c)

(a)

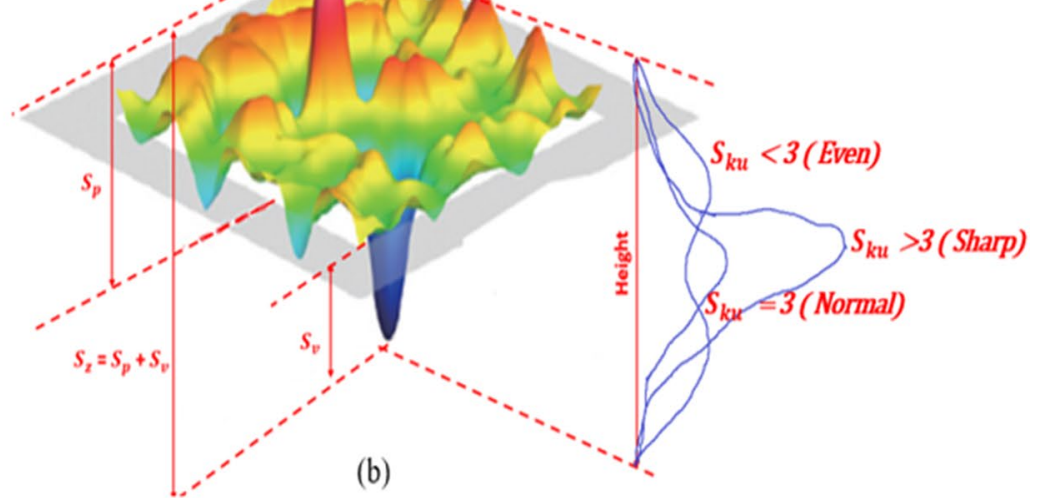

Fig. 7 a-c Graphical representation of three-dimensional roughness parameters for the scaled surface portion 


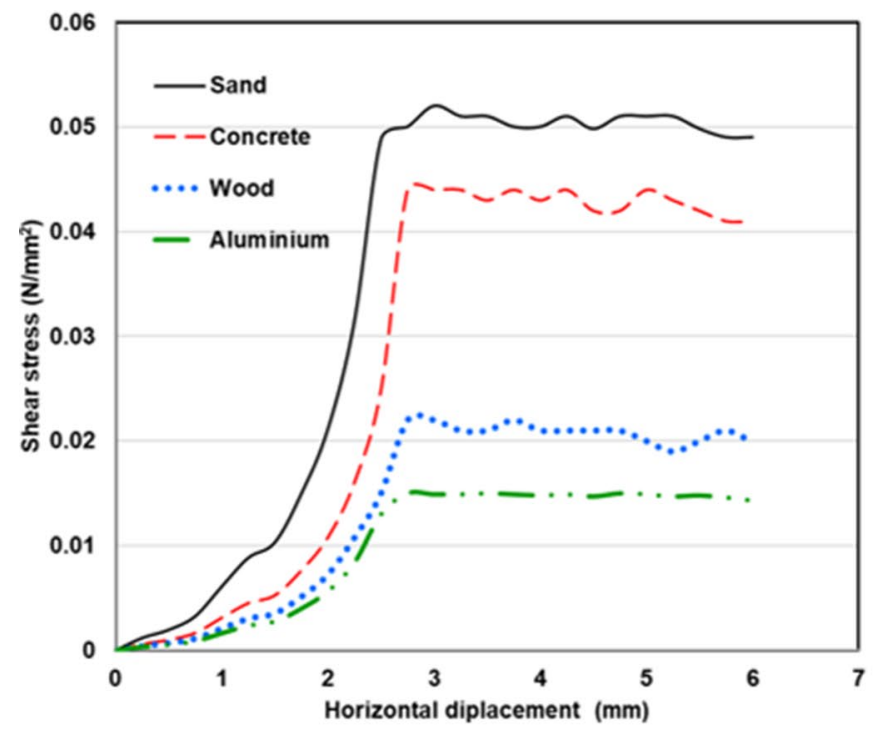

(a)

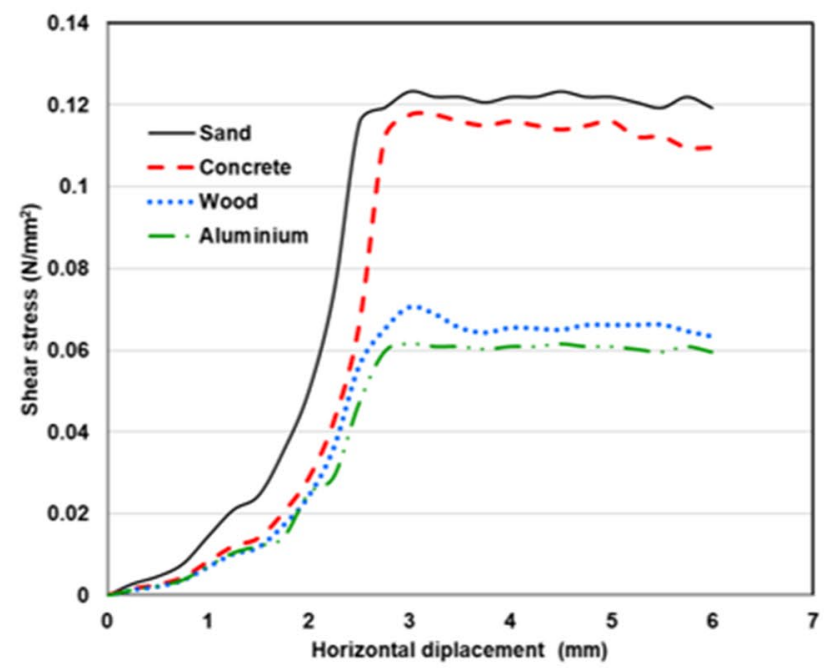

(c)

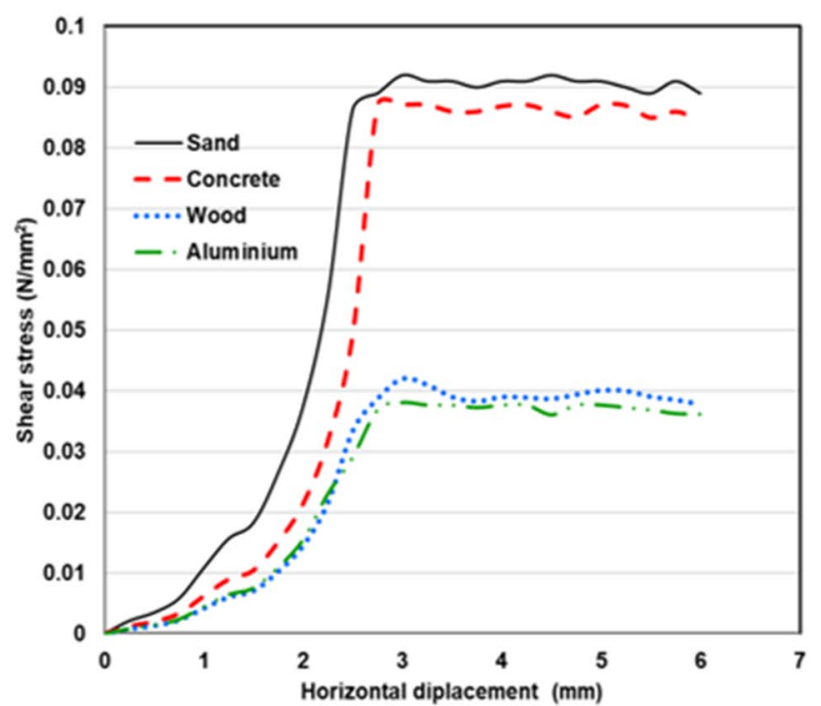

(b)

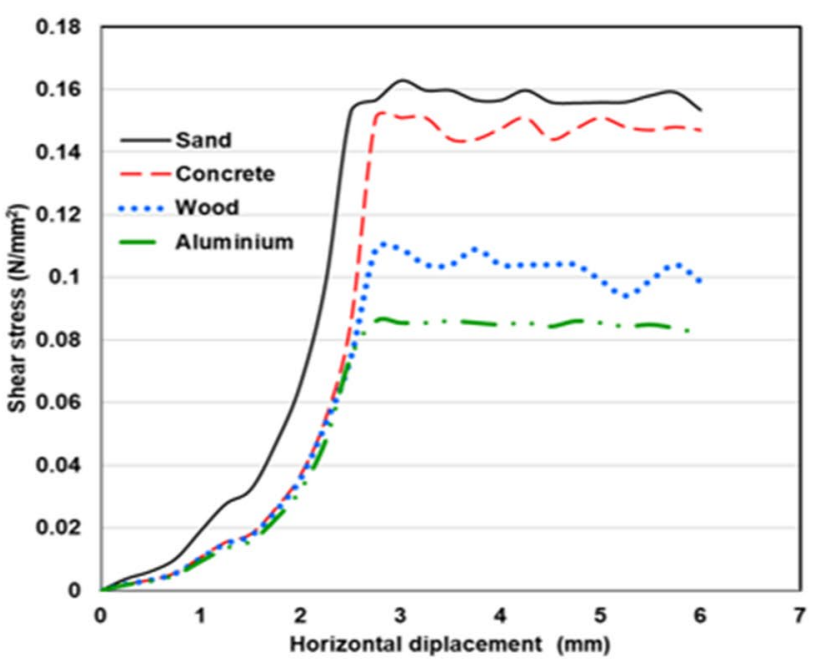

(d)

Fig. 8 Shear displacement behaviour of Sand, Concrete, Wood, and Aluminium interfaces at four different normal stresses $\left(0.05 \mathrm{~N} / \mathrm{mm}^{2}, 0.10 \mathrm{~N} /\right.$ $\mathrm{mm}^{2}, 0.15 \mathrm{~N} / \mathrm{mm}^{2}$ and $0.20 \mathrm{~N} / \mathrm{mm}^{2}$ ): a-d Shear stress-shear displacement

increase in cohesion values of the concrete specimen from 0.012 to $0.0131 \mathrm{~N} / \mathrm{mm}^{2}$. The enhanced interlocking actions in interfacial regions and the increased roughness provided by concrete specimens contributed towards improved cohesion values. As a result, an increased shear band development with significant dilative strain would develop in the soil around the concrete pile shaft, contributing to a higher pile skin resistance.

Due to the lack of surface adhesive characteristics, wood and aluminium specimen reported negative cohesion values $\left(-0.0118 \mathrm{~N} / \mathrm{mm}^{2},-0.0089 \mathrm{~N} / \mathrm{mm}^{2}\right)$, as shown in Table 2 . The post shear cohesion values did not show improvement, indicating that interfacial sand particles experienced greater slipping near the surface of the specimen rather than within the sand particles. The estimation of interfacial parameters through direct shear tests may not measure micro surface irregularities, especially near contact zones. Consequently, as detailed in the sections below, three-dimensional surface profilometric experiments are conducted to investigate the surface contours of the pile materials pre and post shear tests.

\section{Surface profile characteristics of concrete, wood and aluminium plate specimens pre (before) and post (after) shear test}

Figure 10 shows the comparison of the roughness profile along the length for (a) Concrete, (b) Wood (c) Aluminium 
Fig. 9 Variation of peak and post peak shear stress versus normal stress with sand, concrete, wood and aluminium specimens

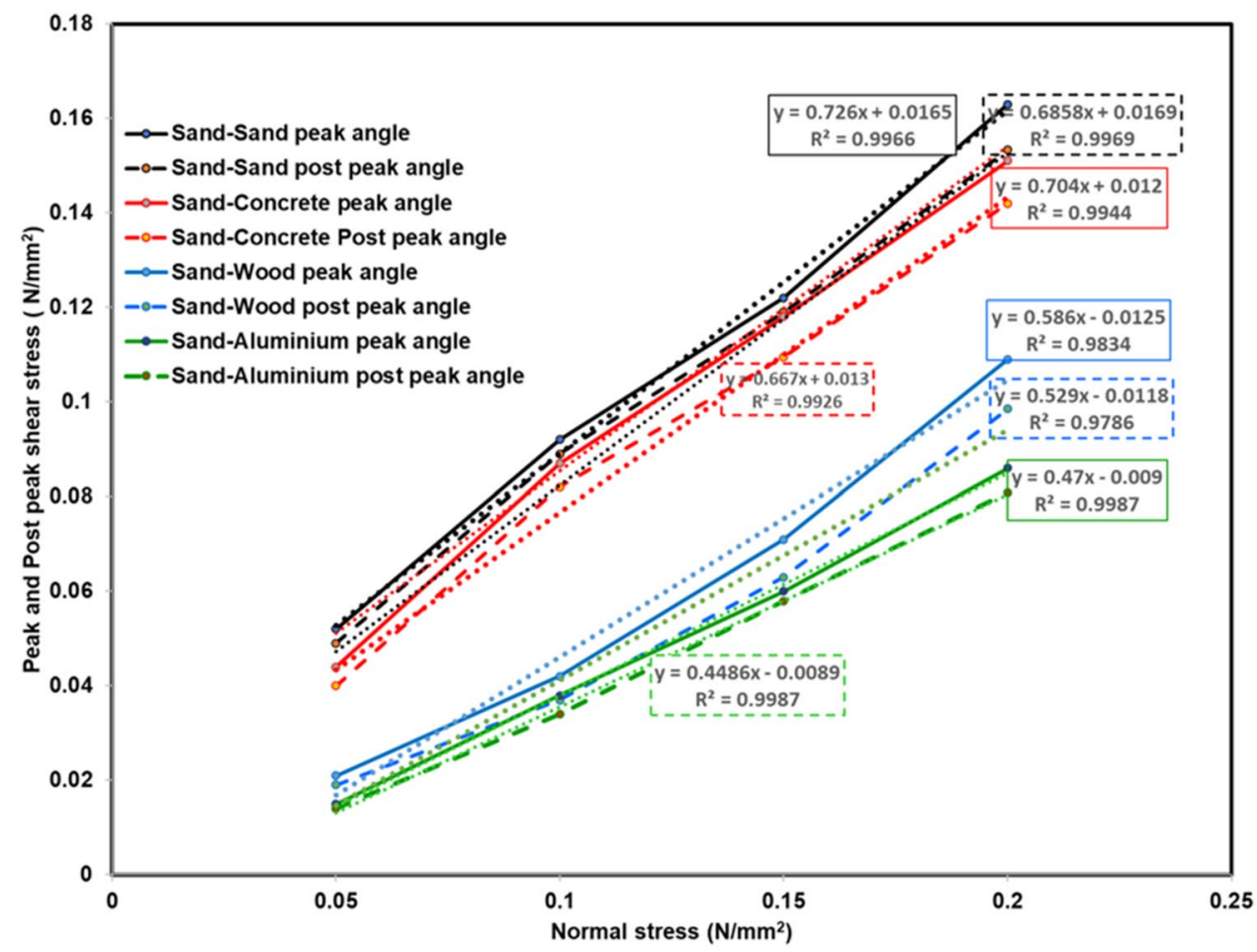

Table 2 Variation of peak and post peak interfacial parameters

\begin{tabular}{lllllr}
\hline Serial No & $\begin{array}{l}\text { Interfacial interaction } \\
\text { type with sand }\end{array}$ & $\begin{array}{l}\text { Peak angle of internal/inter- } \\
\text { face friction }(\varphi)\end{array}$ & $\begin{array}{l}\text { Peak cohesion }(\mathrm{c}, \\
\left.\mathrm{N} / \mathrm{mm}^{2}\right)\end{array}$ & $\begin{array}{l}\text { Post peak angle of internal/ } \\
\text { interface friction }\left(\varphi^{\prime}\right)\end{array}$ & $\begin{array}{l}\text { Post peak cohe- } \\
\text { sion }\left(\mathrm{c}^{\prime}, \mathrm{N} / \mathrm{mm}^{2}\right)\end{array}$ \\
\hline 1 & Sand & $36.07^{\circ}(0.73)$ & 0.0165 & $34.44^{\circ}(0.69)$ & 0.0169 \\
2 & Concrete & $34.69^{\circ}(0.69)$ & 0.0120 & $33.71^{\circ}(0.67)$ & 0.0131 \\
3 & Wood & $29.74^{\circ}(0.57)$ & -0.0125 & $27.87^{\circ}(0.53)$ & -0.0118 \\
4 & Aluminium & $25.31^{\circ}(0.47)$ & -0.0090 & $24.13^{\circ}(0.45)$ & -0.0089 \\
\hline
\end{tabular}

following pre(before) and post (after) shear test. Along the profile's length, positive values corresponding to peak denotes higher tangential and adhesion forces, whereas negative values corresponding to valleys indicate lower tangential and adhesion forces [21]. In the concrete specimen's surface profile before the shear test, many peaks and valleys spotted at different points on the surface due to the concrete's rough-textured nature. But after the shearing process, there is an enhancement in surface roughness of the concrete surface due to the rubbing action of granular particles on rough concrete material. For wood and aluminium specimens, the enhancement of peaks and valleys are less because both materials offered higher tangential and rolling action after the shearing effect.

\section{Effect of roughness parameters on the Interface friction angle}

For a scaled surface, the three-dimensional optical profilometer computes roughness parameters such as centre line absolute roughness $R_{a}$, normalised interface roughness $R_{n}$ and relative material ratio $R_{m r}$. Figure 10 shows twodimensional profile measurements for three pile materials. From these figures, the different roughness parameters are estimated and summarised in Table 3, along with interfacial friction angles obtained after the shear tests.

Table 3 shows that the variation in different roughness parameters is significantly less before the shear tests. However, the variation of these parameters is relatively high for different materials after the tests. The rubbing and abrasive actions of infill have created impressions on the surface, which has led to an increase in the interfacial friction of different pile materials. The absolute roughness $R_{a}(\mu \mathrm{m})$ is reported as highest for the concrete specimen $\left(R_{a}=3.40 \mu \mathrm{m}\right)$ and least for aluminium plate $\left(R_{a}=1.84 \mu \mathrm{m}\right)$, which indicates its increased skin friction capacity as a pile material. The $R_{a}$ ( $\mu \mathrm{m}$ ) for wood increased from $2.06 \mu \mathrm{m}$ to $4.89 \mu \mathrm{m}$ and $R_{n}$ values increased from 0.012 to 0.038 due to the reorientation of grains produced by the surface shearing effect of well-graded 

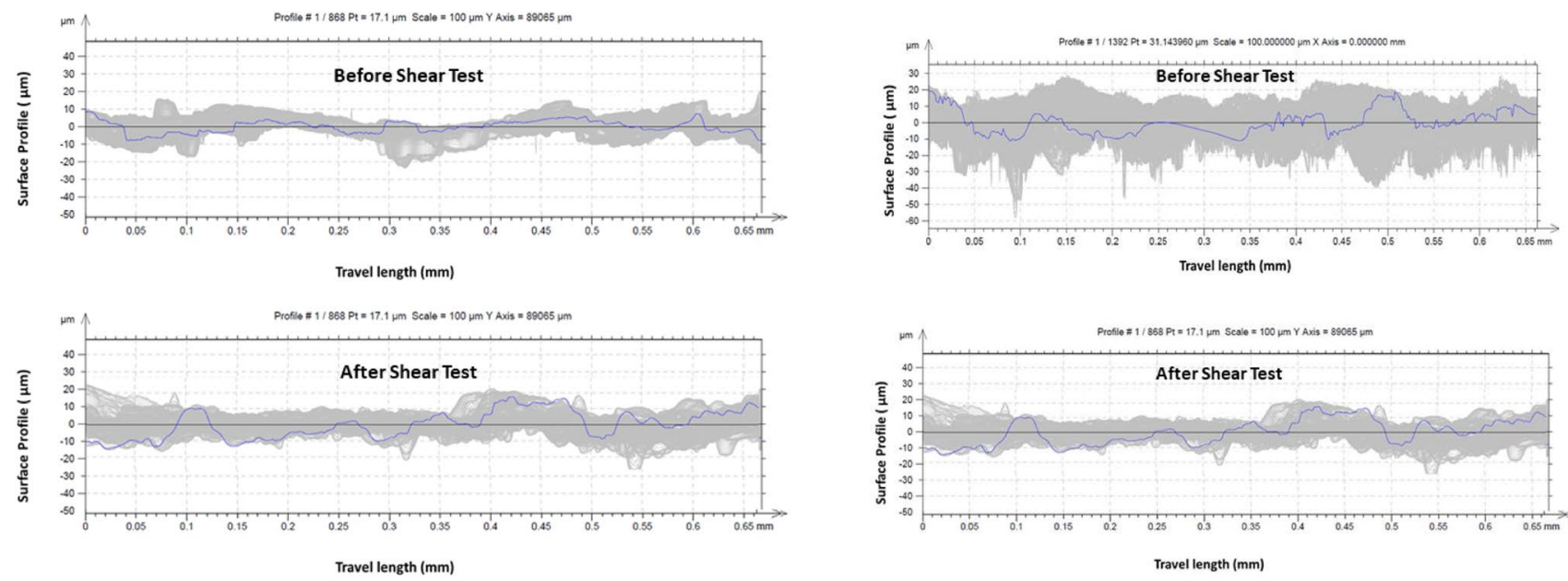

(a) Concrete specimen before and after shear test

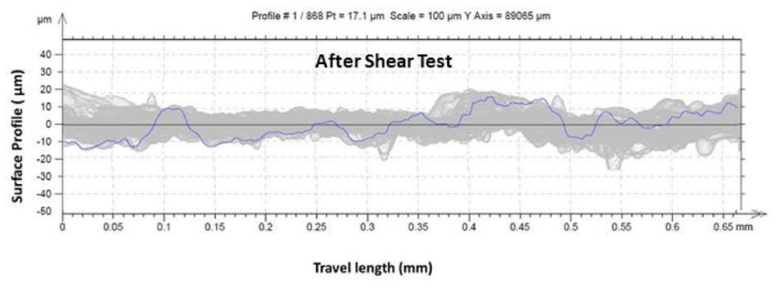

(b) Wood specimen before and after shear test
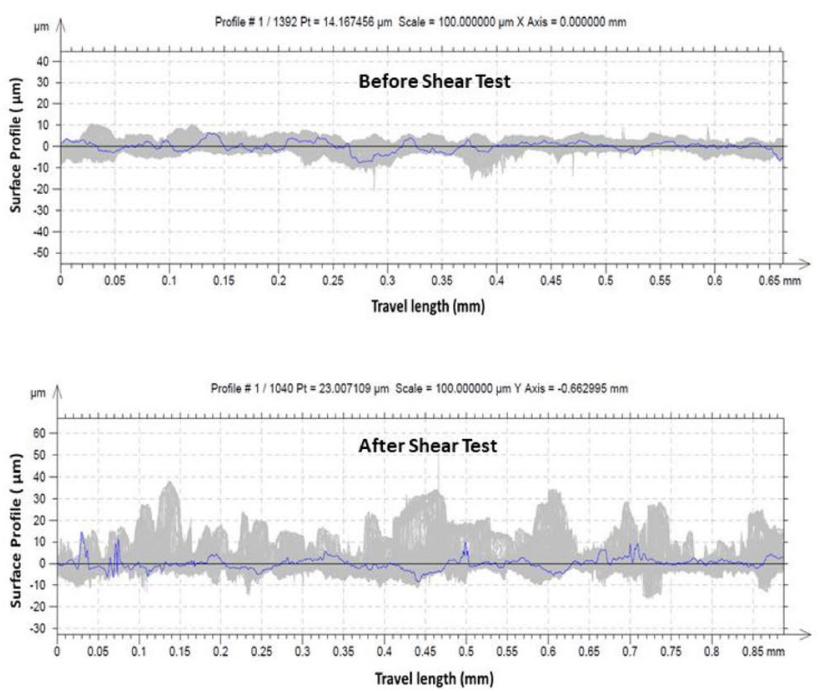

(c) Aluminium specimen before and after shear test

Fig. 10 Roughness profile along the length of specimen for $\mathbf{a}$ concrete plate, $\mathbf{b}$ wood plate, $\mathbf{c}$ aluminium plate pre (before) and post (after) shear test

Table 3 Surface roughness values of materials used in the study

\begin{tabular}{|c|c|c|c|c|c|c|c|c|}
\hline \multicolumn{4}{|l|}{ Before shear tests } & \multicolumn{5}{|l|}{ After shear tests } \\
\hline Type of material & $R_{a}(\mu \mathrm{m})$ & $R_{t}(\mu \mathrm{m})$ & $R_{m r}(\%)$ & $\begin{array}{l}\text { Peak angle of inter- } \\
\text { nal/interface friction } \\
(\varphi)\end{array}$ & $R_{a}(\mu \mathrm{m})$ & $R_{t}(\mu \mathrm{m})$ & $R_{n}=\frac{R t}{D_{50}}$ & $R_{m r}(\%)$ \\
\hline Concrete & 3.40 & 24.4 & 12.3 & $34.69^{\circ}$ & 9.08 & 74.04 & 0.047 & 3.75 \\
\hline Wood & 2.06 & 18.76 & 9.58 & $29.74^{\circ}$ & 4.89 & 59.63 & 0.038 & 5.54 \\
\hline Aluminium & 1.84 & 15.81 & 12.96 & $25.31^{\circ}$ & 3.86 & 43.51 & 0.027 & 8.19 \\
\hline
\end{tabular}

sand. Due to the transition in surface texture from smoother to rougher faces, $R_{a}(\mu \mathrm{m})$ for aluminium increased from $1.84 \mathrm{~m}$ to $3.86 \mathrm{~m}$, and $R_{n}$ values increased from 0.01 to 0.027 . For all three materials, there is an increase in normalised roughness $R_{n}$ or interfacial friction characteristics after shearing actions. Han et al. (2018) reported improved interlocking behaviour for the sand-concrete interface by mobilising the internal peakstate friction angle[17]. For sand-wood with a friction angle of $29.74^{\circ}$ value of $R_{n}$ increased from 0.012 to 0.038 and for sand-aluminium with a peak value of $25.31^{\circ}, R_{n}$ increased from 0.010 to 0.027 . In all these cases, since the value of 
$R_{n}>0.01$, shearing occurs within the sand particle than at the interface region[17].

The $R_{m r}$ indicates the material ratio as a function of the section height and indicates surface undulations over the profile section. The material ratio values evaluate the surface's behaviour that comes into solid-solid mechanical contact. For concrete, there is a decrease in $R_{m r}$ values from 12.3 to $3.75 \%$ (or $67 \%$ decrease) due to the predominance of increased mobilised surface friction between the contact surfaces. However, the decrease in $R_{m r}$ values are around $42 \%$ and $37 \%$ for wood and aluminium due to lesser surface undulations causing interfacial slipping. As a result, it is critical to investigate the interfacial bonding behaviour between the material and soil to maintain the monolithic performance of composite structures at the interface region. So, the subsequent section illustrates the interactive relationship between the interface angle ratio $\left(\varphi^{\prime} / \varphi\right)$ and roughness parameters: normalised interface roughness $R_{n}$ and absolute roughness $R_{a}$.

\section{Variation of post peak-state friction angle ratio $\left(\varphi^{\prime} / \varphi\right)$, normalised interface roughness $R_{n}$ and absolute roughness $R_{a}$}

Figure 11 shows the variation of Post peak-state friction angle ratio $\left(\varphi^{\prime} / \varphi\right)$, relative material ratio roughness $R_{m r}$ and absolute roughness $R_{a}$ for all three different specimens as a component of the centre line average roughness $R_{a}$ and relative material ratio $R_{m r}$. It is evident from the results that $\left(\varphi^{\prime} / \varphi\right)$ is heavily dependent on interface roughness and that a clear relationship exists with the rolling action of the material expressed in terms of $R_{m r}$ and parametric shear ratio $\left(\varphi^{\prime} / \varphi\right)$. With an increase in $\left(\varphi^{\prime} / \varphi\right)$, the Relative material ratio $R_{m r}$ seems to be sloping upwards that indicates the suitability of adopting rougher material for pile construction as it contributes to the skin friction component of pile capacity. So it can be inferred that a relationship exists between the post-peak-state friction angle ratio $\left(\varphi^{\prime} / \varphi\right)$, relative material ratio, $R_{m r}$ and absolute roughness, $R_{a}$. The following section illustrates the isometric views of pile materials and their topographic analysis results. The waviness and asperity of the surface profile of the material are determined using Root means square height, Skewness, Kurtosis, Peak height, Pit width, and Maximum height values. These values also aid in understanding surface bonding characteristics such as rolling, adhesion, and stability between material particles and soil layers.

\section{Three-dimensional surface profile for concrete, wood and aluminium plate specimens pre (before) and post (after) shear test}

The 3D surface profile assists in assessing the skin friction parameter of pile materials by measuring

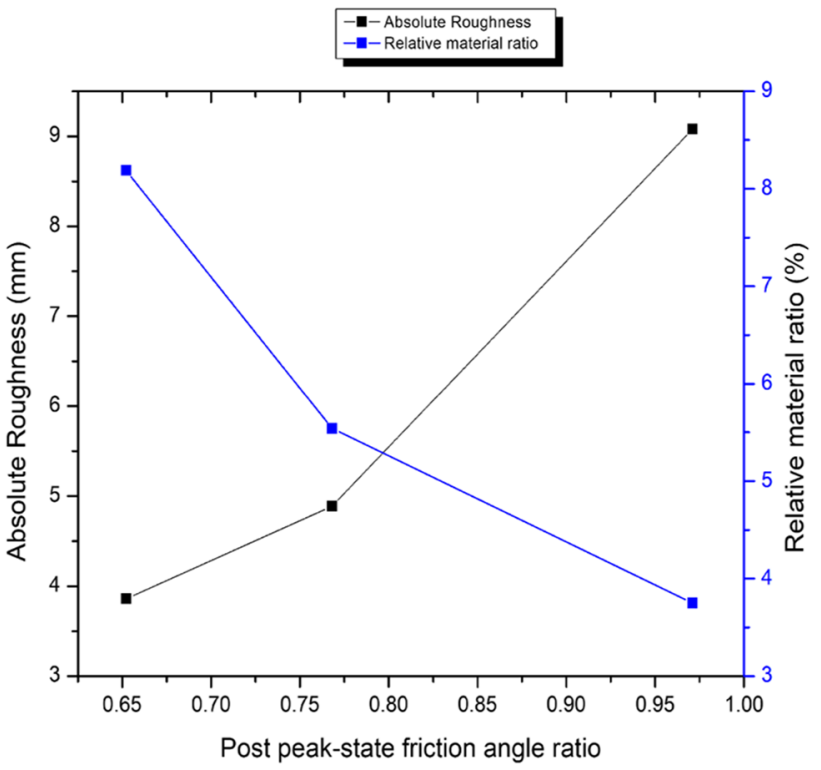

Fig. 11 Variation of Post peak-state friction angle ratio $\left(\varphi^{\prime} / \varphi\right)$, Relative material ratio and Absolute roughness $R_{a}$

three-dimensional surface topography [13, 17, 21, 35]. Figure 12 shows the 3D surface profile for three materials viz; concrete, wood, aluminium.

Table 4 represents the plate specimens' maximum height parameters at pre (before) and post(after) shear test for normal stress $\left(2.0 \mathrm{~N} / \mathrm{mm}^{2}\right)$ as per ISO 4287:1997 [30].

The following section presents a discussion on pre and post shear surface analysis for the plate specimens at normal stress $\left(2.0 \mathrm{~N} / \mathrm{mm}^{2}\right)$ as per (ISO4287:1997) [30].

- The parameter root-mean-square height, $S_{q}$ represents the variation in amplitude of surface unevenness, and it increased for the concrete specimen from 1.82 to $6.38 \mu \mathrm{m}$; wood specimen from 2.36 to $3.23 \mu \mathrm{m}$; aluminium specimen value of $S_{q}$ increased from 2.57 to $2.84 \mu \mathrm{m}$. Surface unevenness, being a material property, is the highest for concrete and least for aluminium before and after the shear test.

- The parameter analysed is Skewness, $S_{s k}$ that measures the surface's undulations with positives values indicating larger contact forces like tangential and adhesion forces than Gaussian cases [21]. Among all the three materials, the Skewness coefficient of concrete drastically increased from 2.05 to 4.44 compared to the other two materials due to the abrasive action generated between concrete surface adhesions. The twodimensional study reports the reduced values of $R_{m r}$ values for concrete specimen. For wood and aluminium specimens, $S_{s k}$ values increased from 1.38 to 3.55 and 1.24 to 2.64 which indicates the rolling action of sand on those surfaces. 

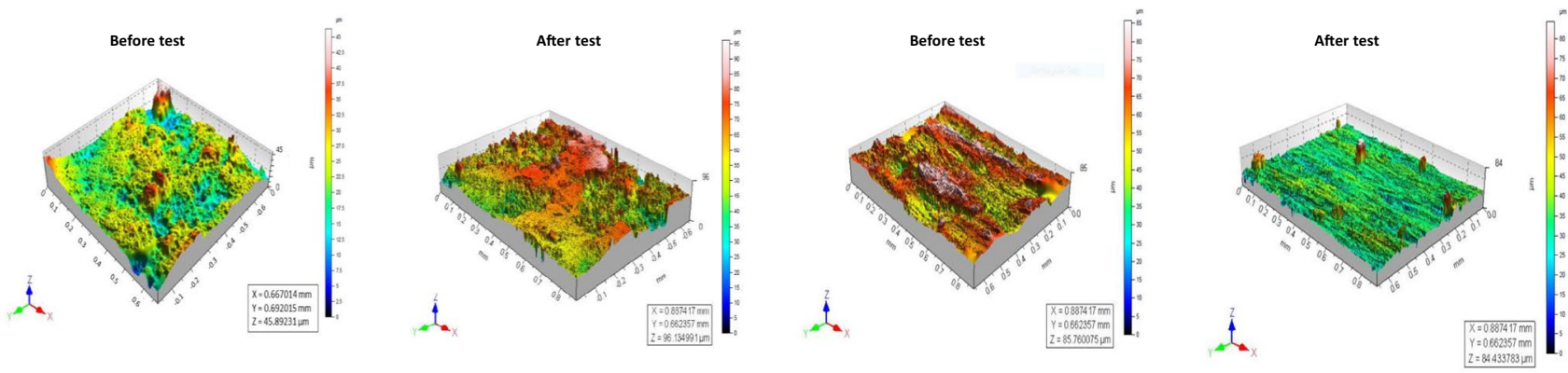

(a) Concrete specimen before and after the shear test

(b) Wood specimen before and after the shear test
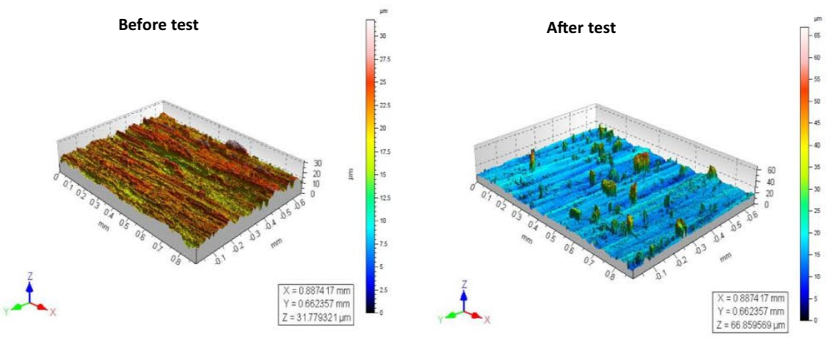

(c) Aluminium specimen before and after the shear test

Fig. 12 Three-dimensional surface roughness profile pre (before) and post (after) shear test: a concrete, $\mathbf{b}$ wood, $\mathbf{c}$ aluminium

Table 4 Height parametersroughness profile (maximum values) parameters for the plate specimens at pre (before) and post(after) shear test for normal stress $\left(2.0 \mathrm{~N} / \mathrm{mm}^{2}\right)$ as per ISO 4287:1997 [30]

\begin{tabular}{lllcc}
\hline Material & Parameters & Description & Before shear & After shear \\
\hline Concrete & Root mean square height & $S_{q}(\mu \mathrm{m})$ & 1.82 & 6.38 \\
& Skewness & $S_{s k}$ & 2.05 & 4.44 \\
& Kurtosis & $S_{k u}$ & 5.77 & 3.63 \\
& Peak height (maximum) & $S_{p}(\mu \mathrm{m})$ & 34.57 & 64.54 \\
& Pit depth (maximum) & $S_{v}(\mu \mathrm{m})$ & 10.8 & 34.91 \\
Wood & Maximum height & $S_{z}(\mu \mathrm{m})$ & 44.58 & 94.57 \\
& Root mean square height & $S_{q}(\mu \mathrm{m})$ & 2.36 & 3.23 \\
& Skewness & $S_{s k}$ & 1.38 & 3.55 \\
& Kurtosis & $S_{k u}$ & 3.28 & 3.40 \\
& Peak height (maximum) & $S_{p}(\mu \mathrm{m})$ & 49.16 & 53.48 \\
& Pit depth (maximum) & $S_{v}(\mu \mathrm{m})$ & 35.43 & 23.58 \\
& Maximum height & $S_{z}(\mu \mathrm{m})$ & 84.56 & 79.87 \\
& Root-mean-square height & $S_{q}(\mu \mathrm{m})$ & 2.57 & 2.84 \\
& Skewness & $S_{s k}$ & 0.64 & 1.26 \\
& Kurtosis & $S_{k u}$ & 3.01 & 6.98 \\
& Peak height (maximum) & $S_{p}(\mu \mathrm{m})$ & 20.07 & 30.54 \\
& Pit depth (maximum) & $S_{v}(\mu \mathrm{m})$ & 12.94 & 12.59 \\
& Maximum height & $S_{z}(\mu \mathrm{m})$ & 32.24 & 43.78 \\
\hline
\end{tabular}

- The Kurtosis parameter, $S_{k u}$ is adopted to measure the sharpness of pits and peaks present on the surface. There is flattening of peaks and pits in the concrete surface profile, and it agrees with the $R_{m r}$ values observed in the table. The kurtosis value decreased for the concrete specimen, though it increased for the Wood and Aluminium specimens. The value follows leptokurtic distribution $\left(S_{k u}\right)>3$ with flatter tails than the normal distribution. For the case of the concrete specimen, $S_{k u}$ decreased from 5.77 to 3.63 , mainly due to increased shear resistance, as seen in Fig. 12. For wood specimen, $S_{k u}$ value increased from 3.28 to 3.40 , indicating the formation of a few distinct peaks and pits after shearing. The variation in the Kurtosis value is most 
Table 5 Comparison of interfacial wall friction values from literature and experimental works

\begin{tabular}{|c|c|c|c|}
\hline \multirow{2}{*}{$\begin{array}{l}\text { Type of soil-struc- } \\
\text { ture interface }\end{array}$} & \multicolumn{3}{|c|}{ Interfacial friction angle between pile wall and soil } \\
\hline & $\begin{array}{l}\text { The present study (post } \\
\text { peak friction angle) }\end{array}$ & $\begin{array}{l}\text { Design aids for pile construc- } \\
\text { tion[42] (post peak friction } \\
\text { angle) }\end{array}$ & $\begin{array}{l}\text { Indian code of practice } \\
\text { [37] (post peak friction } \\
\text { angle) }\end{array}$ \\
\hline Concrete-sand & $33.71^{\circ}$ & $27.05^{\circ}$ & $22.96^{\circ}$ \\
\hline Wood-sand & $27.87^{\circ}$ & $24.16^{\circ}$ & $22.96^{\circ}$ \\
\hline Aluminium-sand & $24.13^{\circ}$ & _- & _- \\
\hline
\end{tabular}

significant for aluminium surface, i.e. 3.01 to 6.98 , due to higher peak formation after shearing action.

- The parameters like Maximum Peak height $S_{p}$, Pit depth $S_{v}$, Maximum height $S_{z}$ reached higher values post shear tests.

The significance of roughness characteristics and the adequacy of international codes in estimating pile friction and improvising pile design guidelines based on pile material characteristics is always a matter of discussions. International codes outlined the design, installation, and maintenance of pile foundations, but the significance of surface roughness values in estimating piles' friction capacity has been discussed only by few codes [36-40]. For instance, some codes suggested that the pile skin friction angle for concrete and timber piles can range from $2 / 3$ or $3 / 4$ times of post-peak friction angle $[37,40]$. This assumption leads to more conservative estimations of pile capacity. The American Petroleum Institute (API) gave recommendations for offshore-driven piles' design and discussed the selection of pile diameter, pile shaft thickness, stiffness properties, weight, and length of piles [39]. But on the other hand, the roughness characteristics of pile materials have not given much consideration in pile design calculations. The skin friction factor used for pile design was based on interfacial friction angle and depended on infill conditions. In Indian codes of pile practices for the design of substructures, the skin friction component of bearing capacity was calculated based on interfacial friction between pile wall surface and the infill material [36, $38,41]$. Furthermore, pile material's roughness properties (pile wall friction) was found proportional to the soil friction angle around the pile shaft region.

The design aids for pile design and construction proposed few empirical relations to estimate skin friction between different foundation materials and soil [42]. For concrete as interface material in clean fine to medium sand conditions, the friction angle of pile material is taken as 0.75 times the friction angle of contact soil. The steel material in clean sand to silty sand has a $20^{\circ}-17^{\circ}$, whereas timber has a friction angle of 0.67 times the infill's internal friction angle. Table 5 shows the comparison of interfacial wall friction values from literature as well as from experimental works.
From Table 5, it is evident that estimation of pile friction angle through international codes offered conservative results of skin friction components compared to experimental inter-frictional data[37, 42]. The experimental data from the present studies reported an enhancement in friction angle values since it depended upon pile material characteristics, infill medium and state of shear-induced stresses.

\section{Conclusions}

Though experimental studies can estimate interfacial friction, topographical studies are beneficial for analysing surface texture and interpreting the mechanical behaviour of interfaces. Here, interfacial shear tests integrated with microscopic studies are employed to understand soil-pile material interface behaviour. The suitability of pile material assessed through friction angle ratio, material ratio, and roughness parameters concluded that rougher materials are desirable for pile construction since they increase the skin friction component of pile capacity. For concrete specimen, the predominance of increased mobilised surface friction between the contact surfaces decreased the relative material ratio $R_{m r}$ values. The Relative material ratio $R_{m r}$ of wood and aluminium specimens featured a marginal decrease due to smaller surface undulations leading to higher interfacial slipping. From the three pile surfaces tested, the abrasive action of infill on concrete is more evident in the form of peaks and valleys. Though the infill could create distinct peaks and valleys on the surface of wood and aluminium, the undulations are not uniform due to the higher tangential and rolling action after the shearing effect. The kurtosis value followed leptokurtic distribution in all three cases and decreased for the concrete specimen due to increased surface resistance. The value increased due to distinct peaks and pits after shearing for the wood specimen, whereas for aluminium specimen, variation in Kurtosis value is most significant due to higher peak formation after shearing action. The investigation about the sufficiency of international codes in assessing pile skin friction revealed heavy dependence of codes on the infill material's friction angle rather than interfacial frictional values, leading to conservative skin friction components. But the microscopic studies proved 
their feasibility in capturing adhesion or cohesion factor, coefficient of friction, rubbing and rolling action of solid surfaces near interface regions. The shear-induced interfacial friction studies can assess the material's durability and propose suitable structural retrofitting methods for enhancing the performance of the construction material when used for substructures.

Authors' contributions GS: Experimental modelling, Writing-original draft, Formal analysis. MNA: Conceptualisation, Formal analysis, Review \& editing. LT: Preparation of material and testing of materials.

Funding This research received no specific grant from any funding agency in the public, commercial, or not-for-profit sectors.

Availability of data and materials The datasets generated during and analysed during the current study are available from the corresponding author on reasonable request.

Code availability Not applicable.

\section{Declarations}

Ethics approval and consent to participate Not applicable.

Consent for publication Not applicable.

Competing interests The authors declare that they have no competing interests.

\section{References}

1. Stauffer ST, Stauffer S (2016) Performance assessment of deteriorated and retrofitted steel HP piles. University of Nebraska-Lincoln

2. Eugene K-H, Kim Bassem Andrawes (2016) Load rating and FRP retrofitting of bridge abutment timber piles. University of Illinois at Urbana-Champaign

3. Parsons JD (1936) Progress report on an investigation of the shearing resistance of cohesionless soils. In: Proceedings of the 1st international conference on soil mechanics and foundation engineering, pp 1-87

4. Roscoe KH (1953) An apparatus for the application of simple shear to soil samples. In: Proceedings of 3rd ICSMFE, pp 186-191

5. Kishida H, Uesugi M (1987) Tests of the interface between sand and steel in the simple shear apparatus. Geotechnique 37:45-52. https://doi.org/10.1680/geot.1987.37.1.45

6. Uesugi M, Kishida H, Tsubakihara Y (1998) Behaviour of sand particles in sand steel friction. Soils Found 28:107-118

7. Terzaghi K, Peck RB, Mesri G (1967) Soil mechanics in engineering practice. Wiley-Interscience Publication

8. Potyondy JG (1961) Skin friction between various soils and construction materials. Géotechnique 11:339-353

9. David Frost J, DeJong JT, Recalde M (2002) Shear failure behavior of granular-continuum interfaces. Eng Fract Mech 69:20292048. https://doi.org/10.1016/S0013-7944(02)00075-9

10. Frost JD, DeJong JT (2005) In situ assessment of role surface roughness on interface response. J Geotech Geoenvironmental
Eng 131:498-511. https://doi.org/10.1061/(ASCE)10900241(2005)131:4(498)

11. DeJong JT, David Frost J, Sacs M (2018) Relating quantitative measures of surface roughness and hardness to geomaterial interface strength. In: ISRM international symposium 2000, IS 2000

12. Ho TYK, Jardine RJ, Anh-Minh N (2011) Large-displacement interface shear between steel and granular media. Geotechnique 61:221-234. https://doi.org/10.1680/geot.8.P.086

13. Vangla P, Latha Gali M (2016) Effect of particle size of sand and surface asperities of reinforcement on their interface shear behaviour. Geotext Geomembranes 44:254-268. https://doi.org/ 10.1016/j.geotexmem.2015.11.002

14. Jeong SW, Park SS (2019) Effect of the surface roughness on the shear strength of granular materials in ring shear tests. Appl Sci. https://doi.org/10.3390/app9152977

15. Wang YB, Zhao C, Wu Y (2020) Study on the effects of grouting and roughness on the shear behavior of cohesive soil-concrete interfaces. Materials (Basel) 13:12-25. https://doi.org/10.3390/ ma13143043

16. Wilson R, Dini D, Van Wachem B (2017) The influence of surface roughness and adhesion on particle rolling. Powder Technol 312:321-333. https://doi.org/10.1016/j.powtec.2017.01.080

17. Han F, Ganju E, Salgado R, Prezzi M (2018) Effects of interface roughness, particle geometry, and gradation on the sandsteel interface friction angle. J Geotech Geoenvironmental Eng 144:10-16. https://doi.org/10.1061/(ASCE)GT.1943-5606.00019 90

18. Namjoo AM, Toufigh MM, Toufigh V (2019) Experimental investigation of interface behaviour between different types of sand and carbon fibre polymer. Eur J Environ Civ Eng. https://doi.org/10. 1080/19648189.2019.1626290

19. Alawneh AS, Malkawi AIH, Al-deeky H (1999) Tension tests on smooth and rough model piles in dry sand. Can Geotech J $36: 746-753$

20. Canakci H, Hamed M, Celik F et al (2016) Friction characteristics of organic soil with construction materials. Soils Found 56:965972. https://doi.org/10.1016/j.sandf.2016.11.002

21. Muszyński Z, Wyjadłowski M (2019) Assessment of the shear strength of pile-to-soil interfaces based on pile surface topography using laser scanning. Sensors (Switzerland). https://doi.org/10. 3390/s19051012

22. Liu C, Tang X, Wei H et al (2020) Model tests of jacked-pile penetration into sand using transparent soil and incremental particle image velocimetry. KSCE J Civ Eng 24:1128-1145. https://doi. org/10.1007/s12205-020-1643-4

23. Fioravante V (2002) On the shaft friction modelling of non-displacement piles in sand. Soils Found 42:23-33. https://doi.org/10. 3208/sandf.42.2_23

24. El Haffar I, Blanc M, Thorel L (2020) Impact of pile roughness on shaft resistance in sand. Proc Inst Civ Eng Geotech Eng 173:8191. https://doi.org/10.1680/jgeen.18.00135

25. Kim G, Ham K, Lee J (2020) Effects of surface roughness on lateral load-carrying capacities of piles embedded in sand. J Geotech Geoenvironmental Eng 146:1-11. https://doi.org/10.1061/(ASCE) GT.1943-5606.0002308

26. Kou H, Diao W, Zhang W et al (2021) Experimental study of interface shearing between calcareous sand and steel plate considering surface roughness and particle size. Appl Ocean Res 107:102490. https://doi.org/10.1016/j.apor.2020.102490

27. ASTM Standard C128-07a (2010) Standard test method for density, relative density (specific gravity), and absorption of fine aggregate. West Conshohocken, Pennsylvania

28. ASTM Standard D6528-17 (2017) Standard test method for consolidated undrained direct simple shear testing of fine grain soils. West Conshohocken, Pennsylvania 
29. de Groot PJ (2015) Principles of interference microscopy for the measurement of surface topography. Adv Opt Photonics 7:1. https://doi.org/10.1364/aop.7.000001

30. ISO4287:1997 (1997) Geometrical product specifications (GPS)—surface texture: profile method-terms, definition sand surface texture parameters. International standard, Geneva 20, Switzerland

31. ISO 25178-2:2012 (2012) Geometrical product specifications (GPS)—surface texture: Areal—Part 2: Terms, Definitions and Surface Texture Parameters (ISO 25178-2:2012), First. International standard, Geneva 20, Switzerland

32. Arshad MI, Tehrani FS, Prezzzi M, Salgado R (2014) Experimental study of cone penetration in silica sand using digital image correlation. Géotechnique 64:551-569. https://doi.org/10.1680/ geot.13.P.179

33. Wang HL, Zhou WH, Yin ZY, Jie XX (2019) Effect of grain size distribution of sandy soil on shearing behaviors at soil-structure interface. J Mater Civ Eng 31:1-10. https://doi.org/10.1061/ (ASCE)MT.1943-5533.0002880

34. ASME (American Society of Mechanical Engineers) (2010) B46.1: surface texture (surface roughness, waviness, and lay). New York, NY, USA

35. Hegde A, Sitharam TG (2015) Use of Bamboo in soft-ground engineering and its performance comparison with geosynthetics: experimental studies. J Mater Civ Eng 27:1-9. https://doi.org/10. 1061/(ASCE)MT.1943-5533.0001224

36. Indian Standard 2911-Part III (1980) Code of practice for design and construction of pile foundations. Bureau of Indian Standards, New Delhi

37. EN 1997-1 Eurocode 7 (2004) Design of concrete structures-Part 1-1:general rules and rules for buildings. Belgium, 2004, Avenue Marnix, Brussels

38. Indian Standard 2911-Part I (2010) Design and construction of pile foundations - code of practice, part 1: concrete piles, section 1: driven cast in-situ concrete piles. Bureau of Indian Standards, New Delhi

39. American Petroleum Institute (API) (2003) Recommended practice for planning, designing and constructing fixed offshore platforms - working stress design, 20th edn. API Publishing Services, pp 66-68

40. Navfac D (1984) Foundation and earth structures. Naval Facilities Engineering Command Publications

41. Indian Railway Standard (2003) Code of practice for the design of sub-structures and foundations of bridges. Research Design and Standards Organisation, Lucknow

42. Tomlinson MJ, Tomlinson M, Woodward J (1994) Pile design and construction practice, 4 th edn. Taylor \& Francis Group 